\title{
Research on Dynamic Dissolving Model and Experiment for Rock Salt under Different Flow Conditions
}

\author{
Xinrong Liu, ${ }^{1,2}$ Xin Yang, 1,2 Zuliang Zhong, ${ }^{1,2}$ Ninghui Liang, \\ Junbao Wang, ${ }^{3}$ and Ming Huang ${ }^{4}$ \\ ${ }^{1}$ College of Civil Engineering, Chongqing University, Chongqing 400045, China \\ ${ }^{2}$ Key Laboratory of New Technology for Construction of Cities in Mountain Area (Chongqing University), \\ Ministry of Education, Chongqing 400030, China \\ ${ }^{3}$ College of Civil Engineering, Xian University of Architecture and Technology, Xian 710055, China \\ ${ }^{4}$ College of Civil Engineering, Fuzhou University, Fuzhou 350108, China \\ Correspondence should be addressed to Xin Yang; yangxin546@163.com
}

Received 8 December 2014; Accepted 19 January 2015

Academic Editor: João M. P. Q. Delgado

Copyright (C) 2015 Xinrong Liu et al. This is an open access article distributed under the Creative Commons Attribution License, which permits unrestricted use, distribution, and reproduction in any medium, provided the original work is properly cited.

\begin{abstract}
Utilizing deep rock salt cavern is not only a widely recognized energy reserve method but also a key development direction for implementing the energy strategic reserve plan. And rock salt cavern adopts solution mining techniques to realize building cavity. In view of this, the paper, based on the dissolving properties of rock salt, being simplified and hypothesized the dynamic dissolving process of rock salt, combined conditions between dissolution effect and seepage effect in establishing dynamic dissolving models of rock salt under different flow quantities. Devices were also designed to test the dynamic dissolving process for rock salt samples under different flow quantities and then utilized the finite-difference method to find the numerical solution of the dynamic dissolving model. The artificial intelligence algorithm, Particle Swarm Optimization algorithm (PSO), was finally introduced to conduct inverse analysis of parameters on the established model, whose calculation results coincide with the experimental data.
\end{abstract}

\section{Introduction}

Reda and Russo [1] simulated the cavity-building process of the rock salt cavern gas storage by pouring freshwater into the cavity while the brine was discharged. Hagoort [2] established the mathematical model of the rock salt cavity gas storage's injection and production according to the mass and energy equation of natural gas in order to predict the temperature and pressure changes inside the cavities. Hunsche and Schulze $[3,4]$ and Cristescu and Paraschiv $[5,6]$ employed diversified loading methods (single-stage loading with temperature influence considerations and multistage loading) to research rock salt properties in multiple creep stages. Van den Bogert et al. [7] produced the rock salt cavity gas storage pressure model to discuss the geometrical shape and stability of cavities. Wilson et al. [8] built a predictor model to predict cavity shapes based on effects of the injected brine's content, injected speed, and dissolving rate. Han et al. [9] studied stability of a single cavity among the rock salt cavity gas storage and established a mechanical model of the rock salt cavity gas storage which analyzed cavity stability based on effects of rock salt thickness, hardness, cavity shape, and circulation method. Liu et al. [10] studied fractal characteristics of rock salt dissolution. Yaramanci [11] utilized a geoelectric exploration method to assess underground rock salt wastewater disposal sites. Tsang et al. [12] analyzed the excavation of rock salt cavity damage zone according to field tests and theoretical analysis. Wawersik and Preece [13] and Cosenza et al. [14] conducted rock salt permeability measurement for long term safety assessment of storage. Popp and Kern [15] researched the ultrasonic wave velocities, gas permeability, and porosity in natural and granular rock salt. Popp and Kern [16] monitored the state of microfracturing in rock salt during deformation by combined measurements of permeability and P- and S-wave velocities. de Las Cuevas [17] analyzed the pore structure characterization in rock salt. 
TABLE 1: Components of rock salt specimens (\%).

\begin{tabular}{lcc}
\hline Soluble substance & & Insoluble substance \\
\hline $\mathrm{NaCl}$ & $\mathrm{K}_{2} \mathrm{SO}_{3}$ & Small amount of muddy \\
99.4 & 0.4 & 0.2 \\
\hline
\end{tabular}

Stormont [18] studied in situ gas permeability measurements to delineate damage in rock salt. Hampel and Schulze [19] focused on the mechanical properties and constitutive model of rock salt. Yang et al. [20] studied the major risks associated with hydrocarbon storage caverns in bedded salt rock. Zhang et al. [21] researched triaxial creep experiment and constitutive relation of different rock salt. Wang et al. [22] designed a new salt cavern shape design method for use as underground gas storage. Liang et al. [23] found that coupled dissolution and seepage rate significantly impact both transport and mechanical properties of the rock as fabric evolves in a time-dependent manner. Wang et al. [24] researched creep properties and damage model for rock salt under low-frequency cyclic loading.

Past research has yielded significant results for shape control of rock salt cavities and stability analysis. Dynamic dissolving properties of rock salt, however, require further in-depth analysis and research $[25,26]$. In this paper, a dynamic dissolving experiment was designed for rock salt to research the dynamic dissolving process under different flow conditions. And according to experiment results, a dynamic dissolving model for rock salt was built with the finitedifference method applied to derive a numerical solution to the dynamic dissolving model. The Particle Swarm Optimization algorithm was then introduced to inverse parameters of the model. Comparison between the calculation results and experimental data demonstrates effectiveness of the established model and provides reference for the study of the rock salt dissolving mechanism.

\section{Experimental Research on the Rock Salt's Dynamic Dissolving Properties under Different Flow Conditions}

2.1. Experimental Process. Natural rock salt from the Himalayan Mountains in Pakistan was utilized as the experimental specimen. The rock salt is located at a depth of 2000 to 3000 meters and exhibits coloring of white mixed with light red or glass white. Specimens are manufacturer-processed into test specimens of $50 \times 100 \mathrm{~mm}$ for experimental purposes. Components of the specimens are comprised of $99.8 \%$ soluble substance with average density of $2959 \mathrm{~kg} / \mathrm{m}^{3}$ as listed in Table 1.

A water-passage pinhole with $6 \mathrm{~mm}$ diameter is drilled at the center of the sample's axial position and processing conducted strictly in line with the experimental regulations. The processed sample size accuracy must be kept within the deviations. Figure 1 depicts rock salt samples prepared for hole-boring.

Rock salt dynamic dissolving experimental devices (Figure 2) have been designed for this paper. The component

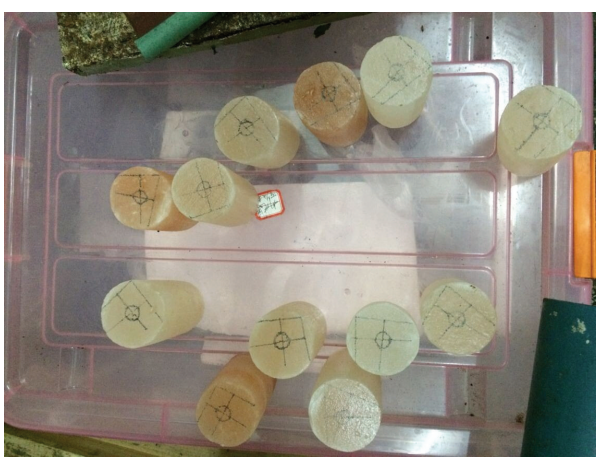

FIGURE 1: Rock salt samples.

devices of the experiment include iron pedestal, beaker chain clip, 703 glue, two large beakers, fluid flowmeter (measuring range $6-60 \mathrm{~L} / \mathrm{h})$, facial tissue, air blower, high-precision electronic balance (the precision is $0.01 \mathrm{~g}$ ), plastic flexible pipe with $6 \mathrm{~mm}$ outer diameter, and vernier calipers.

Test procedures are as follows.

(1) Weigh the bored test sample utilizing the electronic balance and measure length and diameter by vernier calipers.

(2) Seal the test sample utilizing the waterproof coating material "703 glue" and then weigh the sealed samples.

(3) Adjust flow quantity with the water faucet switch to allow the flowmeter to display $20 \mathrm{~L} / \mathrm{h}$.

(4) Attach the beaker chain clip to the waterproofed test sample, insert the water passage pipe into the test sample and begin timing.

(5) Remote the water-passage pipe until three minutes run out and place the pipe into another large beaker for continuation of flow quantity. Then detach the test sample and dry the sample with facial tissue and the air blower and weigh with the electronic balance.

(6) Adjust the flowmeter to display the flow quantity numbers of $30 \mathrm{~L} / \mathrm{h}, 40 \mathrm{~L} / \mathrm{h}$, and $50 \mathrm{~L} / \mathrm{h}$. Repeat experiment procedures in (4) and (5).

2.2. Experimental Results. The rock salt dynamic dissolving curve is not a smooth curve but rather a slightly fluctuating curve as demonstrated in Figures 3 and 4.

Dissolving rate of rock salt accelerates with a larger value of flow quantity $Q$ as demonstrated in Tables 2 and 3, revealing that solution movement accelerated the convection effect and diffusion effect of rock salt. The experiment studied rock salt samples in dynamic solution state, and rock salt specimen dissolving mass was recorded with different flow rates in different time to study the effect of flow quantity $Q$ on the dissolving rate of rock salt. Experiment results reveal that in a certain range the dissolving rate of rock salt increases with increasing of flow quantity $Q$. Therefore, in practice, properly controlling the freshwater injection rate will have a better effect of mineral dissolution for rock salt. 


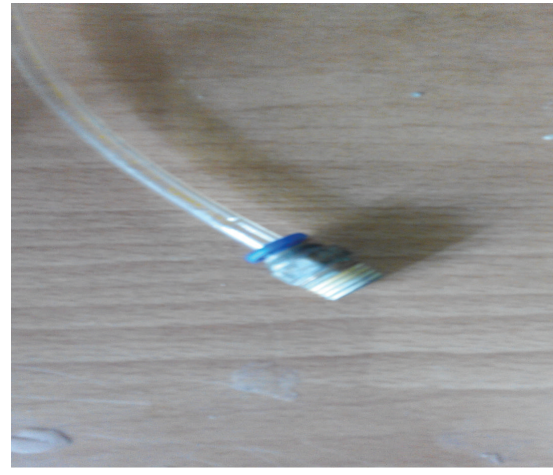

(a) Flexible pipe and joint

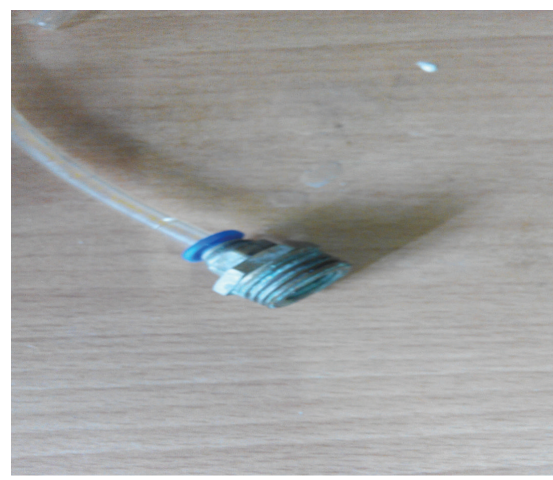

(c) Connect device with (a) and (b)

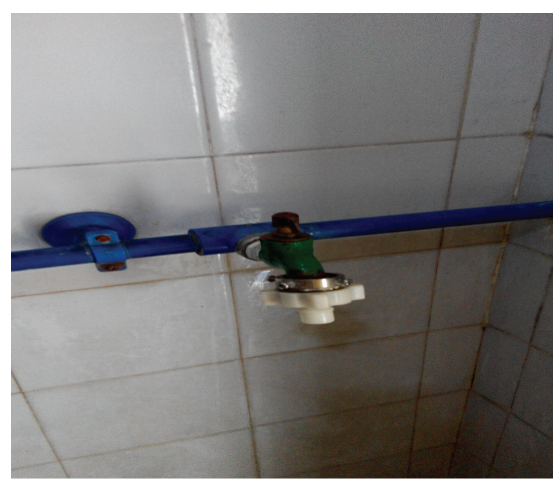

(e) Faucet

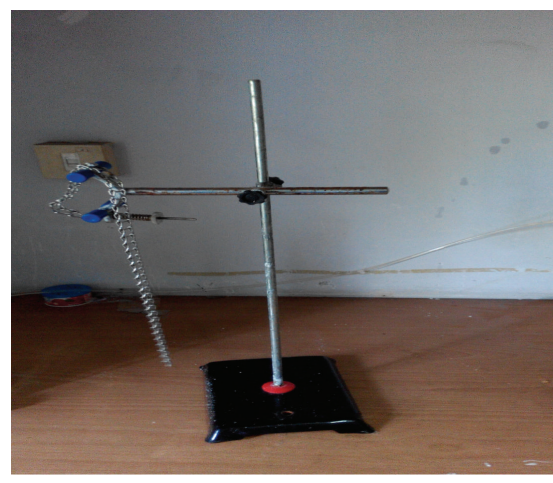

(g) Iron pedestal and beaker chain clip

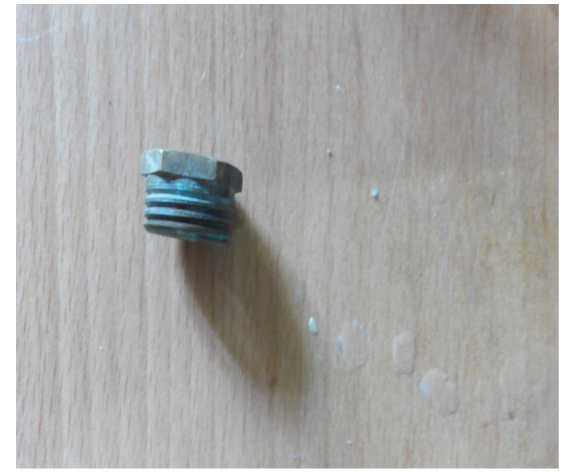

(b) Joint

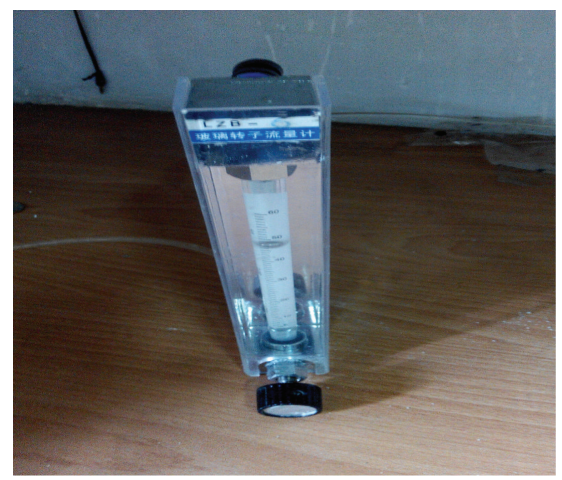

(d) Fluid flowmeter

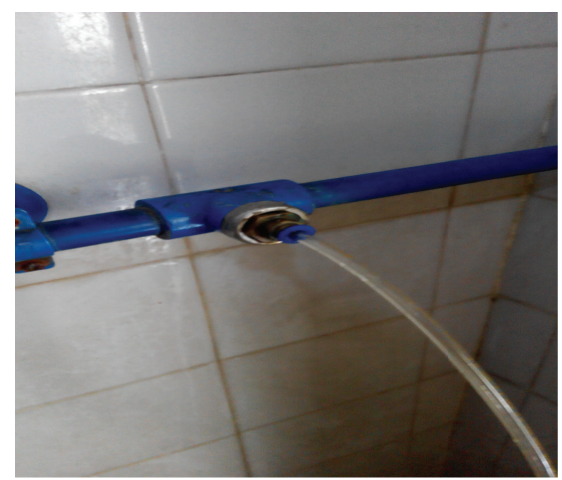

(f) Connect faucet with the device (c)

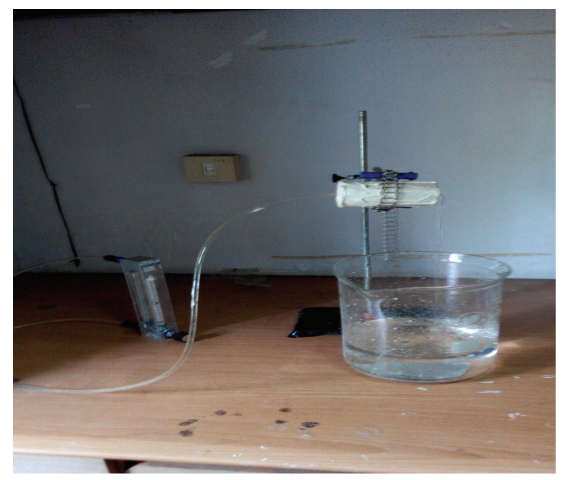

(h) Dynamic dissolving experimental set-up

FIGURE 2: Device for dynamic dissolving test for rock salt. 
TABLE 2: Data of rock salt specimens.

\begin{tabular}{|c|c|c|c|c|c|}
\hline $\begin{array}{l}\text { Serial number of the } \\
\text { test sample }\end{array}$ & Diameter/mm & Length/mm & $\begin{array}{l}\text { Mass of the test } \\
\text { sample/g }\end{array}$ & $\begin{array}{l}\text { Mass of the sample that has been sealed } \\
\text { with waterproof coating materials/g }\end{array}$ & Density $/ \mathrm{g} \cdot \mathrm{cm}^{-3}$ \\
\hline A1 & 49.32 & 100.78 & 394.25 & 434.01 & 2.0797 \\
\hline A2 & 51.84 & 101.08 & 432.54 & 464.3 & 2.0284 \\
\hline A3 & 50.92 & 101.96 & 441.22 & 480.62 & 2.156 \\
\hline A4 & 52.56 & 101.38 & 446.39 & 482.25 & 2.0572 \\
\hline
\end{tabular}

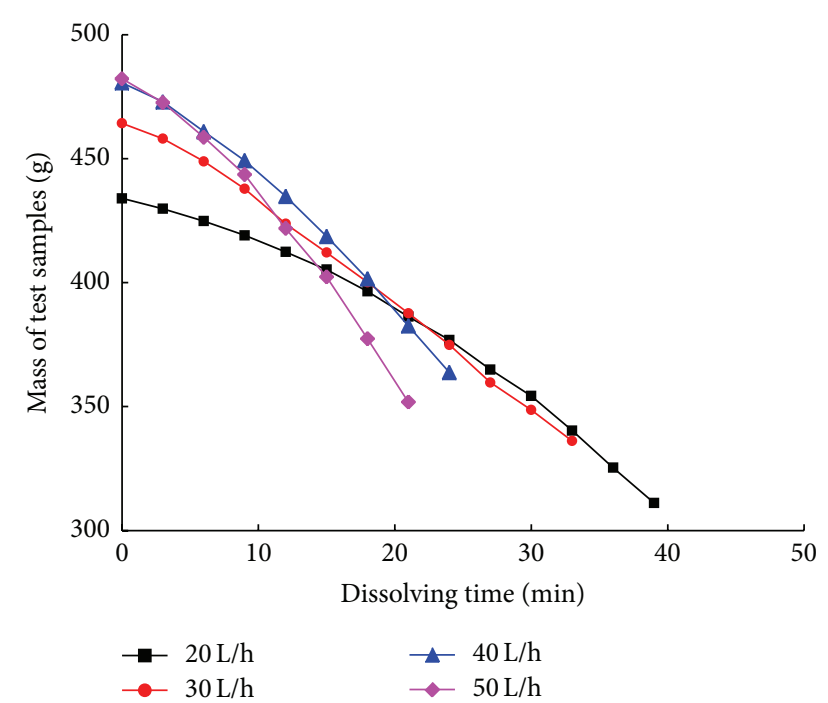

FIGURE 3: The curve of test specimen's mass under different flow quantity.

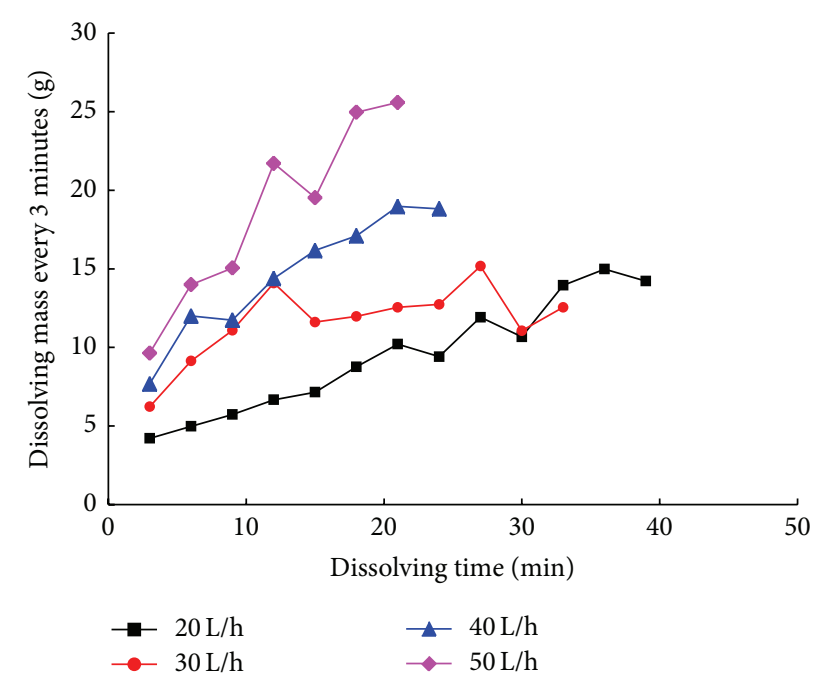

FIGURE 4: The curve of test specimen's dissolving mass every 3 minutes under different flow quantity.

\section{Rock Salt's Dynamic Dissolving Model under Different Flow Conditions}

Ideal conditions are assumed for rock salt samples as follows. (1) Rock salt samples are considered homogeneous
TABle 3: Results of dynamic dissolving test for rock salt (g).

\begin{tabular}{lcccc}
\hline & \multicolumn{4}{c}{ Flow quantity } \\
Time/min & $20 \mathrm{~L} / \mathrm{h}$ & $30 \mathrm{~L} / \mathrm{h}$ & $40 \mathrm{~L} / \mathrm{h}$ & $50 \mathrm{~L} / \mathrm{h}$ \\
& $\mathrm{A} 1$ & $\mathrm{~A} 2$ & $\mathrm{~A} 3$ & $\mathrm{~A} 4$ \\
\hline 0 & 434.01 & 464.3 & 480.62 & 482.25 \\
3 & 429.79 & 458.07 & 472.94 & 472.61 \\
6 & 424.81 & 448.93 & 460.94 & 458.62 \\
9 & 419.08 & 437.85 & 449.2 & 443.57 \\
12 & 412.41 & 423.76 & 434.81 & 421.86 \\
15 & 405.26 & 412.15 & 418.64 & 402.34 \\
18 & 396.49 & 400.18 & 401.54 & 377.38 \\
21 & 386.28 & 387.63 & 382.57 & 351.8 \\
24 & 376.87 & 374.89 & 363.75 & \\
27 & 364.95 & 359.72 & & \\
30 & 354.28 & 348.66 & & \\
33 & 340.33 & 336.11 & & \\
36 & 325.35 & & & \\
39 & 311.13 & & & \\
\hline
\end{tabular}

with isotropic properties and no interlayer. (2) The seepage in dynamic dissolution is considered as laminar flow. (3) Insoluble residuals flow with the fluid and do not subside in the pinhole. (4) Insoluble residuals have a negligible effect on the diffusion process. (5) The influence by temperature difference and variations is ignored.

The diffusion effect can be described according to the First Diffusion Laws of Fick: the diffusion coefficient is directly proportional to the gradient of concentration, described as follows (1):

$$
J=-D \frac{\partial C}{\partial n}
$$

where $J$ represents the diffusive flux $\left(\mathrm{mol} \cdot \mathrm{cm}^{-2} \cdot \mathrm{s}^{-1}\right), C$ refers to the material concentration $\left(\mathrm{mol} \cdot \mathrm{L}^{-1}\right), D$ represents the diffusive coefficient $\left(\mathrm{cm}^{2} \cdot \mathrm{s}^{-1}\right)$, and, under normal circumstances, the diffusive coefficient is relevant to the solvent and temperature of solute.

Micro units $d x$ can be derived according to the mass balance principle and by referring to Figure 5:

$$
J d d x d t=\frac{\rho_{s}}{M} d d R d x
$$

where $\rho_{s}$ refers to the density of rock salt $\left(\mathrm{cm}^{3} \cdot \mathrm{s}^{-1}\right), M$ represents the molar mass of rock salt $\left(\mathrm{g} \cdot \mathrm{mol}^{-1}\right), R$ is 


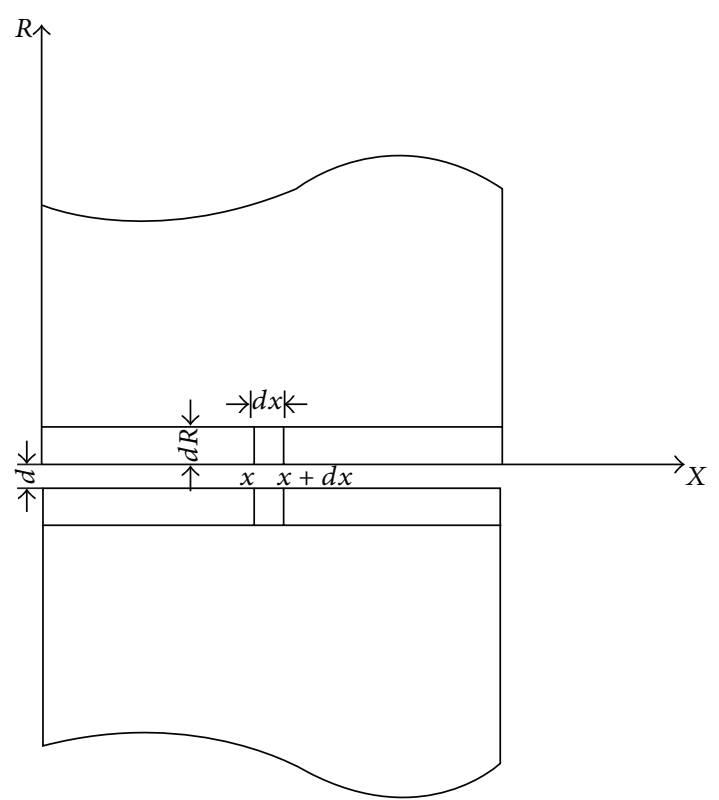

FIgURE 5: Sketch for dynamic dissolution of rock salt.

the dissolving thickness of the rock salt interface $(\mathrm{cm})$, and $d$ represents the diameter of the pinhole $(\mathrm{cm})$.

Combining (1) and (2), the dissolving rate equation of the rock salt wall is established as follows:

$$
\frac{d R}{d t}=-\left.D \frac{M}{\rho_{s}} \frac{\partial C}{\partial n}\right|_{\Gamma_{1}},
$$

where $\Gamma_{1}$ refers to the dissolving interface.

The concentration-distribution curve of the rock salt boundary layer, according to research by Jessen [27], can be regarded as the shape of a para-curve. Assuming the rock salt interface's concentration is $C_{0}$, the mean concentration of the solution beyond the boundary layer is $C_{1}$, the concentration of the solution inside the boundary layer is $C$, the boundary layer's thickness is $\delta$, and the concentration distribution of the dissolving boundary layer can represented by using the following formula:

$$
C-C_{1}=\left(C_{0}-C_{1}\right)\left(1-\frac{z}{\delta}\right)^{2},
$$

where $z$ represents the distance from the interface of rock salt (cm).

Derivatives of (4) can be calculated and presuming the diffusion process is instantly completed, after reorganizing

$$
\left.\frac{\partial C}{\partial n}\right|_{\Gamma_{1}}=-\frac{2}{\delta}\left(C_{s}-C_{x t}\right),
$$

where $C_{s}$ represents saturation concentration of the rock salt solution $\left(\mathrm{mol} \cdot \mathrm{L}^{-1}\right)$ and $C_{x t}$ refers to the concentration of solution at the section position of $x$ with the time of $t$, $\left(\mathrm{mol} \cdot \mathrm{L}^{-1}\right)$.

Substituting (5) into (3),

$$
\frac{d R}{d t}=\frac{2}{\delta} D \frac{M}{\rho_{s}}\left(C_{s}-C_{x t}\right),
$$

where signs mean the same as those appearing before.
The dissolving process of rock salt is also influenced by the fluid's flow rate $v$ and the pinhole diameter $d$. Establishing the dissolving equilibrium equation of rock salt then necessitates the assumption then that $m_{x}$ is the mole number of solution that passes through the pinhole section $x$ within the time period $d t, m_{x+d x}$ refers to the mole number of the solution passing through the seepage section $x+d x$ within the time period $d t$, and $d$ is the diameter of pinhole. The equations are as follows:

$$
\begin{gathered}
m_{x}=C_{x t} \frac{\pi}{4}\left(d+2 R_{x t}\right)^{2} v_{x t} d t \\
m_{x+d x}=\left(C_{x t}+\frac{\partial C}{\partial x} d x\right) \frac{\pi}{4}\left(d+2 R_{x t}\right)^{2} v_{x t} d t .
\end{gathered}
$$

Disregarding changes in the fluid volume inside the pinhole caused by rock salt dissolution, it is discovered, according to the mass balance principle, that the difference between $m_{x+d x}$ and $m_{x}$ is the mole number of the rock salt that has dissolved within the time period of $d t$ at the section $d x$ or

$$
m_{x+d x}-m_{x}=\frac{\rho_{s}}{M} \pi\left(d+2 R_{x t}\right) \partial R \partial x .
$$

Presuming the flow loss is not considered, then

$$
Q=\frac{\pi}{4}\left(d+2 R_{x t}\right)^{2} v_{x t},
$$

where $Q$ represents the flow quantity $\left(\mathrm{cm}^{3} \cdot \mathrm{s}^{-1}\right)$.

Combining (7), (8), and (9), we have the following reorganization:

$$
\frac{\partial C}{\partial x}=\frac{\rho_{s}}{M Q} \pi\left(d+2 R_{x t}\right) \frac{\partial R}{\partial t},
$$

where signs mean the same as those appearing before.

Partial differential equations are composed of (6) and (10):

$$
\begin{gathered}
\frac{\partial R}{\partial t}=\frac{2}{\delta} D \frac{M}{\rho_{s}}\left(C_{s}-C_{x t}\right), \\
\frac{\partial C}{\partial x}=\frac{2 D}{\delta Q} \pi\left(d+2 R_{x t}\right)\left(C_{s}-C_{x t}\right), \\
\left.R_{x t}\right|_{t=0}=0, \\
\left.C_{x t}\right|_{x=0}=C_{0},
\end{gathered}
$$

where $C_{0}$ represents the initial concentration of the solution $\left(\mathrm{mol} \cdot \mathrm{L}^{-1}\right)$.

\section{Numerical Solutions and Results Analysis of Rock Salt Dynamic Dissolving Model under Different Flow Conditions}

4.1. Numerical Solution. Among the rock salt dynamic dissolving models, the partial differential equations (11) are nonlinear, creating challenges for obtaining an analytic solution. 


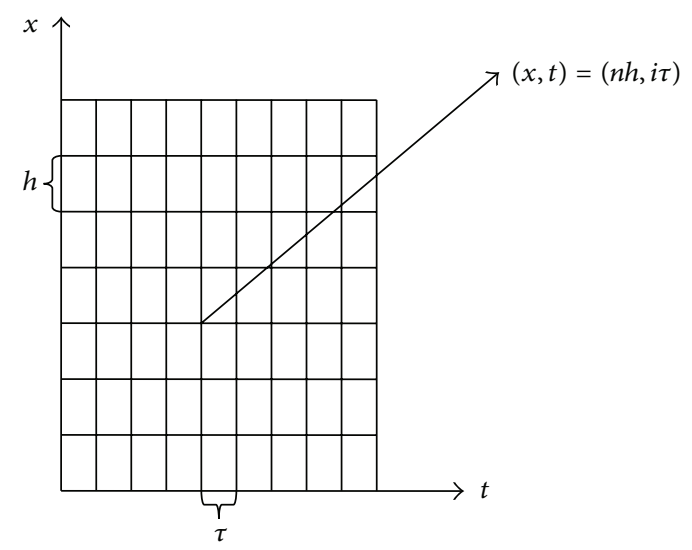

FIGURE 6: Sketch for difference grids.

A proper difference scheme is thus established to discretize the partial differential equations (11). A computerized analytic solution can then be derived.

A difference grid is established as Figure 6, where the step length of $x$ axis is $h$ and the step length of $t$ axis is $\tau$. So $x=n h$ and $t=i \tau$. The equation system then is

$$
\begin{gathered}
R(x, t)=R(n h, i \tau)=R_{i}^{n} \\
C(x, t)=C(n h, i \tau)=C_{i}^{n} \\
\frac{\partial R(x, t)}{\partial t}=\frac{\partial R}{\partial t} \\
\frac{\partial C(x, t)}{\partial x}=\frac{\partial C}{\partial x} .
\end{gathered}
$$

The difference scheme that is built from (11) is as follows:

$$
\begin{gathered}
\frac{R(n h,(i+1) \tau)-R(n h, i \tau)}{\tau}=\frac{2}{\delta} D \frac{M}{\rho_{s}}\left(C_{s}-C(n h, i \tau)\right) \\
\frac{C((n+1) h, i \tau)-c(n h, i \tau)}{h} \\
=\frac{2 D}{\delta Q} \pi(d+2 R(n h, i \tau))\left(C_{s}-C(n h, i \tau)\right) .
\end{gathered}
$$

Assuming that $\left(2 M / \rho_{s}\right) C_{s} \tau=a,\left(2 M / \rho_{s}\right) \tau=b$, $(2 / Q) \pi C_{s} h=A$, and $(2 / Q) \pi h=B$, then after reorganizing:

$$
\begin{gathered}
R_{i+1}^{n}=\frac{D}{\delta}\left(a-b C_{i}^{n}\right)+R_{i}^{n} \\
C_{i}^{n+1}=\frac{D}{\delta}\left(A-B C_{i}^{n}\right)\left(d+2 R_{i}^{n}\right)+C_{i}^{n}
\end{gathered}
$$

then we can get:

$$
\begin{gathered}
R_{i}^{n}=\frac{D}{\delta}\left(a-b C_{i-1}^{n}\right)+R_{i-1}^{n} \\
C_{i}^{n}=\frac{D}{\delta}\left(A-B C_{i}^{n-1}\right)\left(d+2 R_{i}^{n-1}\right)+C_{i}^{n-1},
\end{gathered}
$$

and, further,

$$
\begin{gathered}
R_{i}^{0}=\frac{D}{\delta}\left(a-b C_{i-1}^{0}\right)+R_{i-1}^{0} \\
C_{0}^{n}=\frac{D}{\delta}\left(A-B C_{0}^{n-1}\right)\left(d+2 R_{0}^{n-1}\right)+C_{0}^{n-1} .
\end{gathered}
$$

Owing to known initial conditions, $R(x, 0)=0$ and $C(0, t)=C_{0}$, it is determined that $R_{0}^{n}=0$ and $C_{i}^{0}=C_{0}$. Since the $R_{0}^{n}$ and $C_{i}^{0}$ are known, from the recursion formula, we can also calculate $R_{i}^{0}$ and $C_{0}^{n}$. So the initial conditions $R_{0}^{n}, C_{i}^{0}, R_{i}^{0}$, and $C_{0}^{n}$ will be known.

As known from the recursion equation (15), $R_{i}^{n}=$ $(D / \delta)\left(a-b C_{i-1}^{n}\right)+R_{i-1}^{n}$ is an explicit difference form; in other word, $R_{i}^{n}$ is directly calculated from $R_{i}^{n-1}$ and $C_{i}^{n-1}$. According to initial conditions, $R_{0}^{n}$ has known, and $R_{i}^{n}$ can be calculated through the explicit difference form. Therefore, through the chasing method, from $\left\{C_{i}^{n-1}, R_{i}^{n-1}\right\}$, calculations are made for $\left\{C_{i}^{n}, R_{i}^{n}\right\}$, above is the realization process of the numerical solution.

Parameters of the experiment are as follows: $M=$ $58.5 \mathrm{~g} / \mathrm{mol}, C_{s}=0.0054 \mathrm{~mol} / \mathrm{cm}^{3}$, and $d=0.6 \mathrm{~cm}, \rho_{s}$ and $Q$ can be derived from the experiment and their value referred to in Tables 2 and 3 . The parameters $a, b, A$, and $B$ can then be calculated. The initial concentration of solution in this paper is $C_{0}=0 \mathrm{~mol} / \mathrm{cm}^{3}$.

The diffusion coefficient $D$ and the boundary layer's thickness $\delta$, as determined from the research above, result in the dissolving radius $R$ with the above finite-difference recursion formula applied.

4.2. Parameters Inversion. Particle swarm optimization (PSO), a type of artificial-intelligence algorithm, is introduced in this research to conduce parameters inversion of the rock salt dynamic dissolving model.

Particle swarm optimization is a new Evolutionary Algorithm (EA) developed in recent years. PSO is similar to the Simulated Annealing Algorithm as both originate from random solutions and seek to find optimal solutions through recursion. PSO also evaluates the quality of solutions through fitness value, but is simpler than the Genetic Algorithm rules as it does not have operations such as "Crossover" and "Mutation." PSO simply searches for the global optimum through the found optimal value and is even known for its simplicity, high precision, and quick convergence while demonstrating advantages in the solving of practical problems.

The inverse programs will be realized in the MATLAB software and include three parts (Figure 7). The first part, referred to as cc.Mat, is the random initialization and includes both velocity matrix and position matrix.

The second part, according to the $\mathrm{M}$ file, solves the dissolving radius through applying the finite-difference method programmed on the basis described in Section 4.1 and is referred to as Numerical.m. This part mainly includes the random velocity matrix and random position matrix which are generated in the first part to calculate the dissolving radius $R$. 


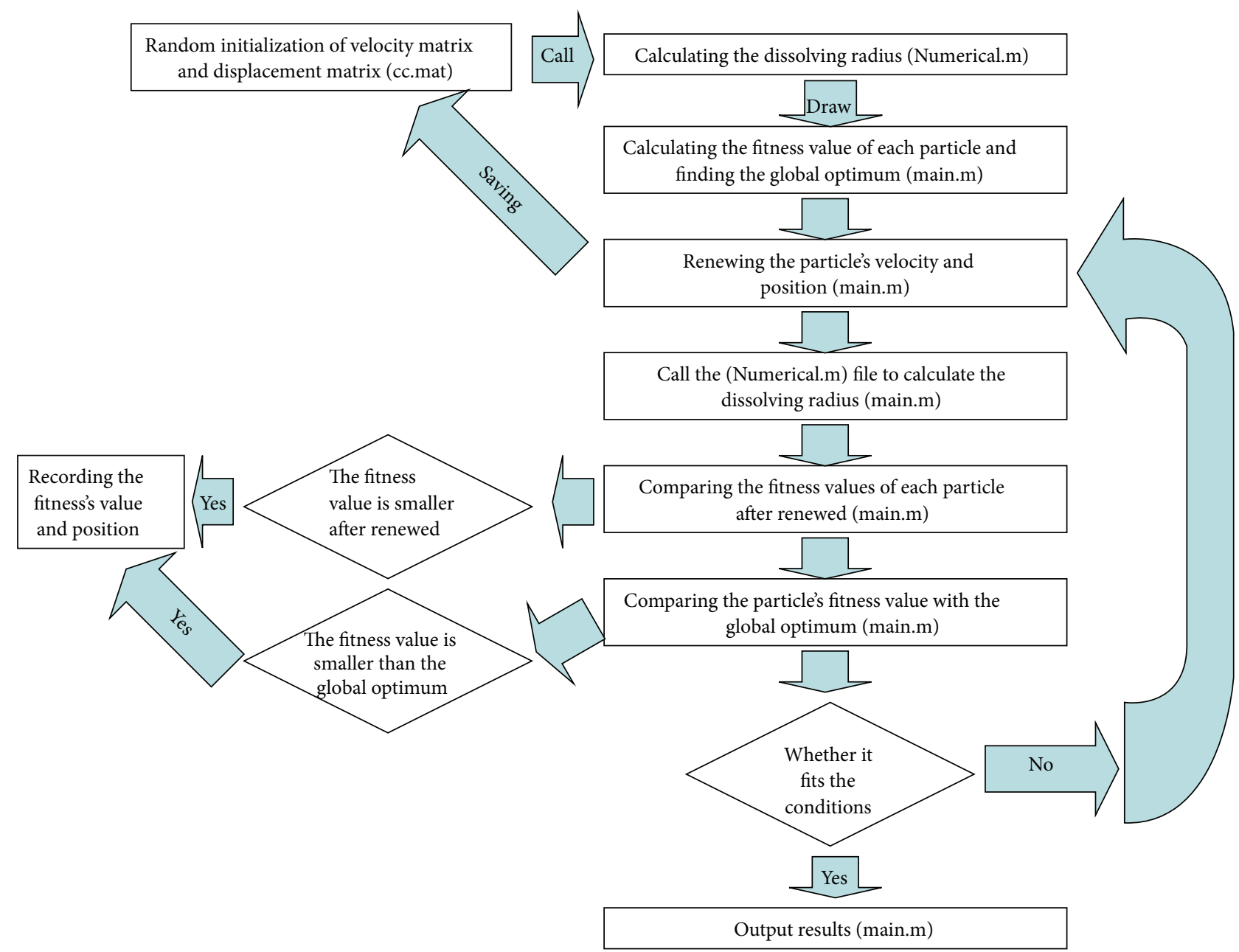

FIGURE 7: Flow chart for program realization.

The third part, referred to as "main.m" is the main program written based on the particle swarm optimization. The program's major steps include

(1) retrieve the cc.Mat file; obtain the random displacement matrix and velocity matrix; implement the Numerical.m file to calculate the dissolving radius $R$; apply the calculated results to the fitness function to attain the fitness value of each particle;

(2) compare the value of each particle's fitness; retrieve the global optimal solution (or the minimum); and record value and position of the global optimum;

(3) update the velocity matrix and position matrix according to the particle swarm optimization; save the renewed data and create overlay for the part one file cc.Mat;

(4) implement the Numerical.m file again after the renewed particle velocity and position matrix and calculate the dissolving radius $R$ and the fitness value of each particle;

(5) compare the fitness value of each particle after renewed. If the upgraded fitness value is smaller, save and record the corresponding value and position. If the value is larger, do not save;

(6) compare the fitness value of each particle after renewed with the global optimum. If the fitness value of the particle with renewed information is smaller, then save and record the value and position. If the value is larger, do not save;

(7) repeat steps (4) to (6) until the conditions for seeking solution are satisfied.

Ren et al. [28] establish the calculation formula of the rock salt's mass and the dissolving radius:

$$
R(k)=\sqrt{\frac{m(k)}{\rho_{s} l \pi}+\frac{d^{2}}{4}}-\frac{d}{2},
$$

where $R(k)$ is the rock salt dissolving radius at the time of $k$, $l$ is the height of the test specimen, and $m(k)$ is the dissolving mass at the time of $t$.

Fitness function can be established as follows:

$$
f=\frac{1}{N} \sum_{k=1}^{N}\left(\sqrt{\frac{m(k)}{\rho_{s} l \pi}+\frac{d^{2}}{4}}-\frac{d}{2}-R\right),
$$




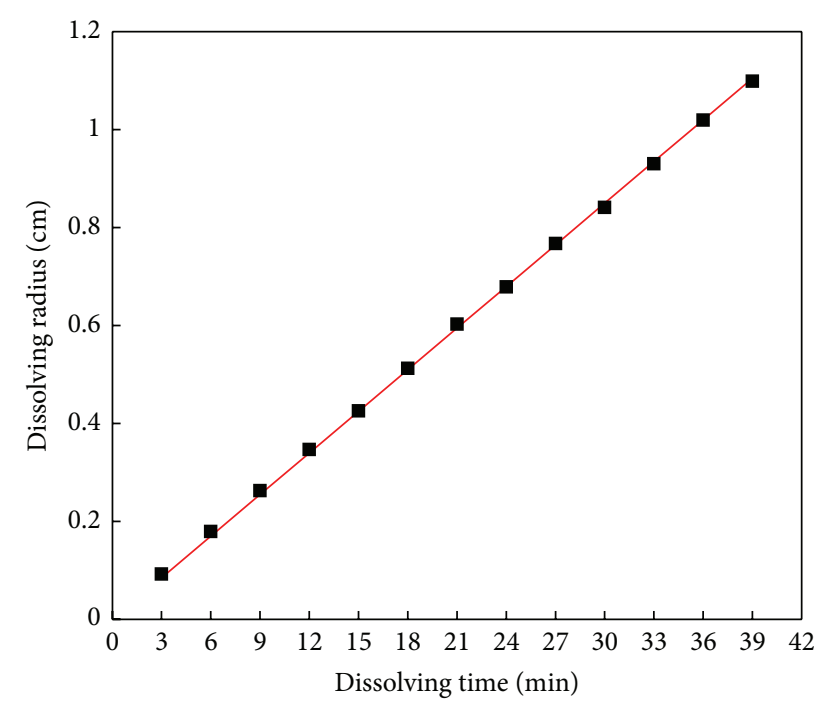

Test data

Calculated results

FIGURE 8: Comparison of the dissolved radius between test data and calculated results under $20 \mathrm{~L} / \mathrm{h}$.

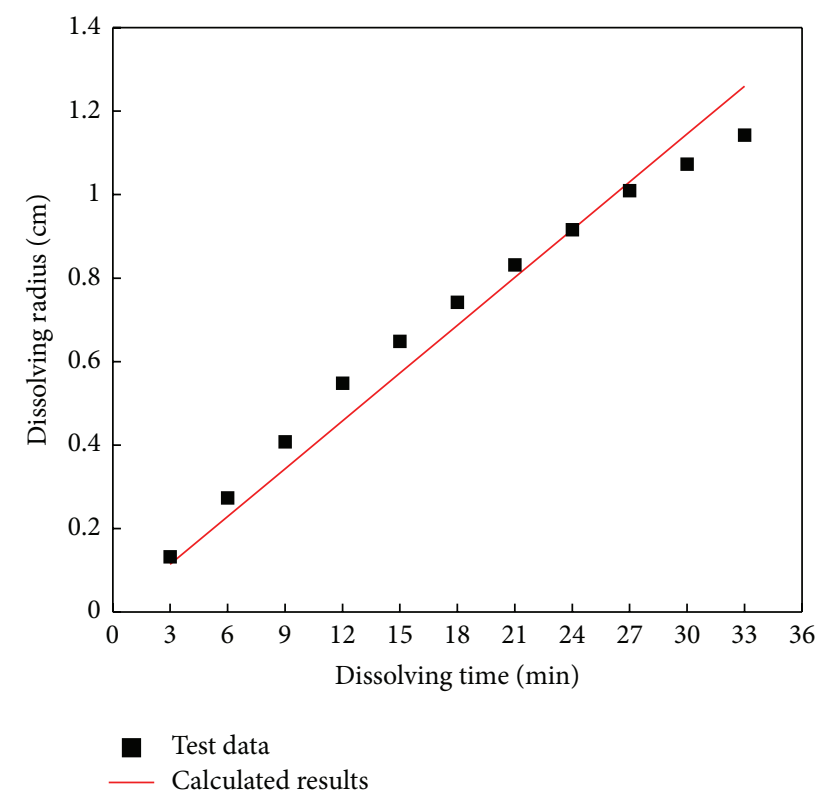

FIGURE 9: Comparison of the dissolved radius between test data and calculated results under $30 \mathrm{~L} / \mathrm{h}$.

where $N$ is the experiment recording times and, as the experiment is recorded every 3 minutes, the total time of the experiment then is $t=N * 180$ (s).

Parameters of rock salt dynamic dissolving models parameters are inversed under different flow conditions according to the particle swarm optimization in this research effort (see Figures 8, 9, 10, and 11). Table 4 details that, with flow $Q$ quantity changing, the increase in flow quantity $Q$ can accelerate the diffusion rate of the rock salt minerals.

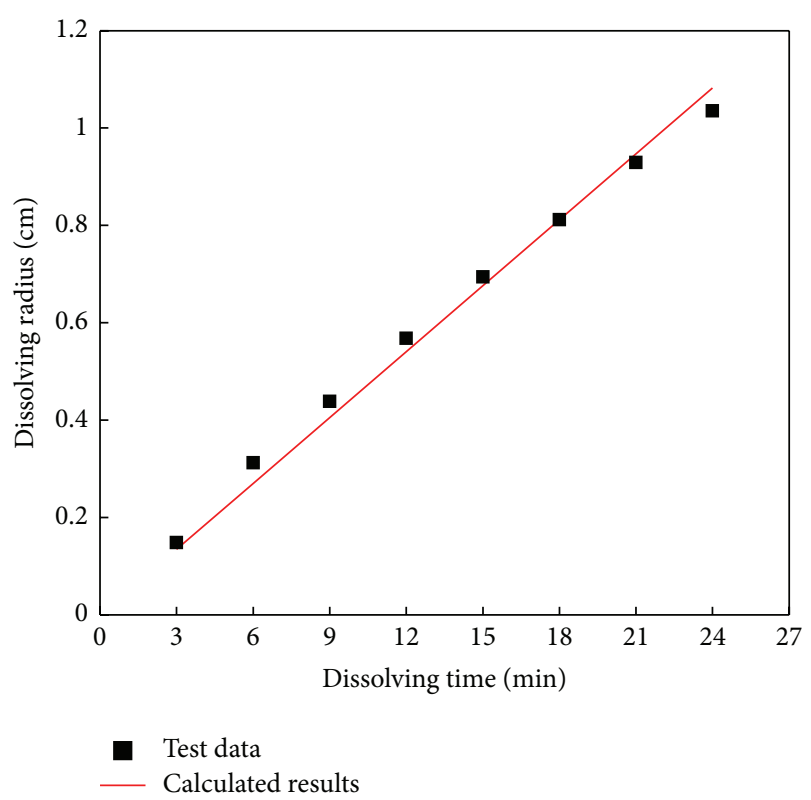

FIGURE 10: Comparison of the dissolved radius between test data and calculated results under $40 \mathrm{~L} / \mathrm{h}$.

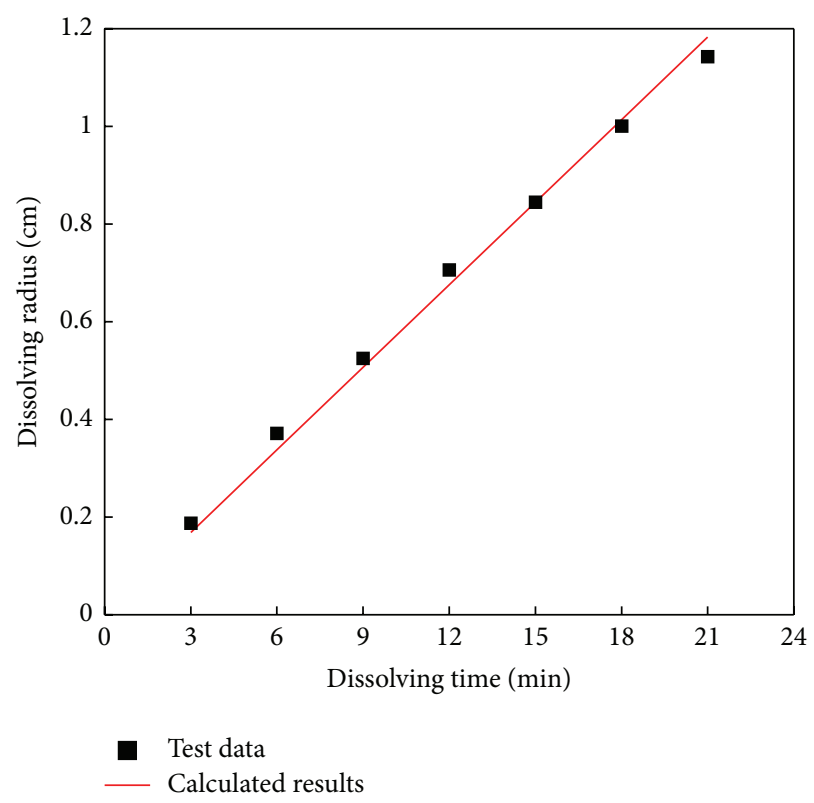

FIGURE 11: Comparison of the dissolved radius between test data and calculated results under $50 \mathrm{~L} / \mathrm{h}$.

\section{Conclusions}

An in-depth and systematic research effort was conducted on the properties of the rock salt dynamic dissolving model and tests under difference flow conditions drawing the following conclusions.

(1) Experimental research on the rock salt dynamic dissolving processes under different flow conditions was conducted by adopting a self-designed rock salt dynamic dissolving experimental set-up. Dynamic 
TABLE 4: Particle swarm optimization algorithm inversion results.

\begin{tabular}{lccc}
\hline $\begin{array}{l}\text { Flow quantity } Q \\
\mathrm{~L} / \mathrm{h}\end{array}$ & $\begin{array}{c}\text { Parameter } D / \delta \\
\mathrm{cm} / \mathrm{s}\end{array}$ & $\begin{array}{c}\text { Fitness value } \\
f\end{array}$ & $\begin{array}{c}\text { Relevance } \\
\text { coefficient } R\end{array}$ \\
\hline 20 & 0.001554 & 0.005234 & 0.9999 \\
30 & 0.002043 & 0.05365 & 0.9923 \\
40 & 0.002567 & 0.02488 & 0.9986 \\
50 & 0.003059 & 0.02211 & 0.9991 \\
\hline
\end{tabular}

dissolving test data of the rock salt was obtained under various flow conditions with varying dissolution time. The dynamic dissolving curve for rock salt was discovered as a fluctuating curve and the dissolving rate of rock salt increased with the increasing of flow quantity $Q$ in a certain range.

(2) According to the dissolving properties of rock salt, the study reasonably simplifies and hypothesizes the rock salt dynamic dissolving process. The study accounts for combined conditions involving the dissolution effect and seepage effect changes of rock salt to establish the rock salt dynamic dissolving model.

(3) The study introduces the particle swarm optimization (PSO) to inverse parameters on the model established by applying the finite-difference method to calculate the numerical solution for the rock salt dynamic dissolving model. Calculation results were found to relatively coincide with the experimental data, indicating the rock salt dynamic dissolving model established is capable of effectively describing the dynamic dissolving process and dissolving mechanisms for rock salt.

\section{Conflict of Interests}

The authors declare that there is no conflict of interests regarding the publication of this paper.

\section{Acknowledgments}

This study is supported by the Fundamental Research Funds for Central Universities of China (Project no. CDJXS12200005), the National Natural Science Foundation of China (Project no. 41202195), and National Key Basic Research Program of China (Project no. 2009CB724606); the authors gratefully acknowledge these supports.

\section{References}

[1] D. C. Reda and A. J. Russo, "Experimental studies of salt-cavity leaching by freshwater injection," SPE 13308, 1986.

[2] J. Hagoort, "Simulation of production and injection performance of gas storage caverns in salt formations," in Proceedings of the SPE Annual Technical Conference and Exhibition, vol. 26654, pp. 505-514, October 1993.

[3] U. Hunsche, "Result and interpretation of creep experiments on rock salt," in Proceedings of the 1st Conference on the Mechanics
Behavior of Salt, H. R. Hardy Jr. and M. Langer, Eds., pp. 159-167, Trans Tech Publications, 1984.

[4] U. Hunsche and O. Schulze, "Effect of humidity and confining pressure on creep of rock salt," in Proceedings of the 3rd Conference on Mechanical Behavior of Salt, pp. 237-248, Trans Tech Publications, Clausthal-Zellerfeld, Germany, 1993.

[5] N. D. Cristescu, "A general constitutive equation for transient and stationary creep of rock salt," International Journal of Rock Mechanics and Mining Sciences \& Geomechanics Abstracts, vol. 30, no. 2, pp. 125-140, 1993.

[6] N. D. Cristescu and I. Paraschiv, "Creep and creep damage around large rectangular-like caverns," Mechanics of CohesiveFrictional Materials, vol. 1, no. 2, pp. 165-197, 1996.

[7] P. A. J. Van den Bogert, E. H. Hoogerduijn, M. C. Eelman, R. M. H. E. van Eijs, and P. D. Richard, "In-situ stress assessment of intra-salt stringers," in SPE/ISRM Rock Mechanics in Petroleum Engineering, Trondheim, Norway, 1998.

[8] S. M. Wilson, P. M. Driscoll, A. Judzis et al., "Drilling salt formations offshore with seawater can significantly reduce well costs," SPE 87216, 2004.

[9] G. Han, M. S. Bruno, K. Lao, J. Young, and L. Dorfmann, "Gas storage and operations in single-bedded Salt caverns: stability analyses," SPE 99520, 2007.

[10] C. Liu, L. Xu, and X. Xian, "Fractal-like kinetic characteristics of rock salt dissolution in water," Colloids and Surfaces A: Physicochemical and Engineering Aspects, vol. 201, no. 1-3, pp. 231-235, 2002.

[11] U. Yaramanci, "Geoelectric exploration and monitoring in rock salt for the safety assessment of underground waste disposal sites," Journal of Applied Geophysics, vol. 44, no. 2-3, pp. 181-196, 2000.

[12] C.-F. Tsang, F. Bernier, and C. Davies, "Geohydromechanical processes in the excavation damaged zone in crystalline rock, rock salt, and indurated and plastic clays-in the context of radioactive waste disposal," International Journal of Rock Mechanics and Mining Sciences, vol. 42, no. 1, pp. 109-125, 2005.

[13] W. R. Wawersik and D. S. Preece, "Creep testing of salt: procedures, problem and suggestions," in Proceedings of the 1st Conference on Mechanical Behavior of Salt, pp. 421-449, Trans Tech Publication, 1981.

[14] P. Cosenza, M. Ghoreychi, B. Bazargan-Sabet, and G. de Marsily, "In situ rock salt permeability measurement for long term safety assessment of storage," International Journal of Rock Mechanics \& Mining Sciences, vol. 36, no. 4, pp. 509-526, 1999.

[15] T. Popp and H. Kern, "Ultrasonic wave velocities, gas permeability and porosity in natural and granular rock salt," Physics and Chemistry of the Earth, vol. 23, no. 3, pp. 373-378, 1998.

[16] T. Popp and H. Kern, "Monitoring the state of microfracturing in rock salt during deformation by combined measurements of permeability and P- and S-wave velocities," Physics and Chemistry of the Earth, Part A: Solid Earth and Geodesy, vol. 25, no. 2, pp. 149-154, 2000.

[17] C. de Las Cuevas, "Pore structure characterization in rock salt," Engineering Geology, vol. 47, no. 1-2, pp. 17-30, 1997.

[18] J. C. Stormont, "In Situ gas permeability measurements to delineate damage in rock salt," International Journal of Rock Mechanics and Mining Sciences, vol. 34, no. 7, pp. 1055-1064, 1997.

[19] A. Hampel and O. Schulze, "The composite dilatancy model: a constitutive model for the mechanical behaviorof rock salt," in The Mechanical Behaviorof Salt-Understanding of THMC Process 
in Salt, M. Wallner, K.-H. Lux, W. Minkley, and H. R. Hardy Jr., Eds., pp. 99-107, Taylor \& Francis, 2007.

[20] C. H. Yang, W. J. Jing, J. J. K. Daemen, G. M. Zhang, and C. Du, "Analysis of major risks associated with hydrocarbon storage caverns in bedded salt rock," Reliability Engineering and System Safety, vol. 113, no. 1, pp. 94-111, 2013.

[21] H. B. Zhang, Z. Y. Wang, Y. L. Zheng, P. J. Duan, and S. L. Ding, "Study on tri-axial creep experiment and constitutive relation of different rock salt," Safety Science, vol. 50, no. 4, pp. 801-805, 2012.

[22] T. T. Wang, X. Z. Yan, H. L. Yang, X. J. Yang, T. T. Jiang, and S. Zhao, "A new shape design method of salt cavern used as underground gas storage," Applied Energy, vol. 104, pp. 50-61, 2013.

[23] W. Liang, Y. Zhao, S. Xu, and M. B. Dusseault, "Dissolution and seepage coupling effect on transport and mechanical properties of glauberite salt rock," Transport in Porous Media, vol. 74, no. 2, pp. 185-199, 2008.

[24] J.-B. Wang, X.-R. Liu, X.-J. Liu, and M. Huang, “Creep properties and damage model for salt rock under low-frequency cyclic loading," Geomechanics and Engineering, vol. 7, no. 5, pp. 569587, 2014.

[25] P. Gorham, D. Saltzberg, A. Odian et al., "Measurements of the suitability of large rock salt formations for radio detection of high-energy neutrinos," Nuclear Instruments and Methods in Physics Research Section A: Accelerators, Spectrometers, Detectors and Associated Equipment, vol. 490, no. 3, pp. 476-491, 2002.

[26] E. Spangenberg, U. Spangenberg, and C. Heindorf, "An experimental study of transport properties of porous rock salt," Physics and Chemistry of the Earth, vol. 23, no. 3, pp. 367-371, 1998.

[27] F. W. Jessen, "Progress report-1) Rate of solution of salt under turbulent flow conditions, 2) Study of mixing effects in salt water, 3) Mechanism of solution and cavity control using intermediate injection, 4) Investigation of multiple well system," Solution Mining Research Institute File 72-0009-SMRI, 1972.

[28] S. Ren, C. Yang, D. Jiang, X. Li, and S. Song, "Development of a new triaxial testing machine with high temperature for dissolution characteristics of salt rock and its application," Chinese Journal of Rock Mechanics and Engineering, vol. 30, no. 2, pp. 289-295, 2011. 

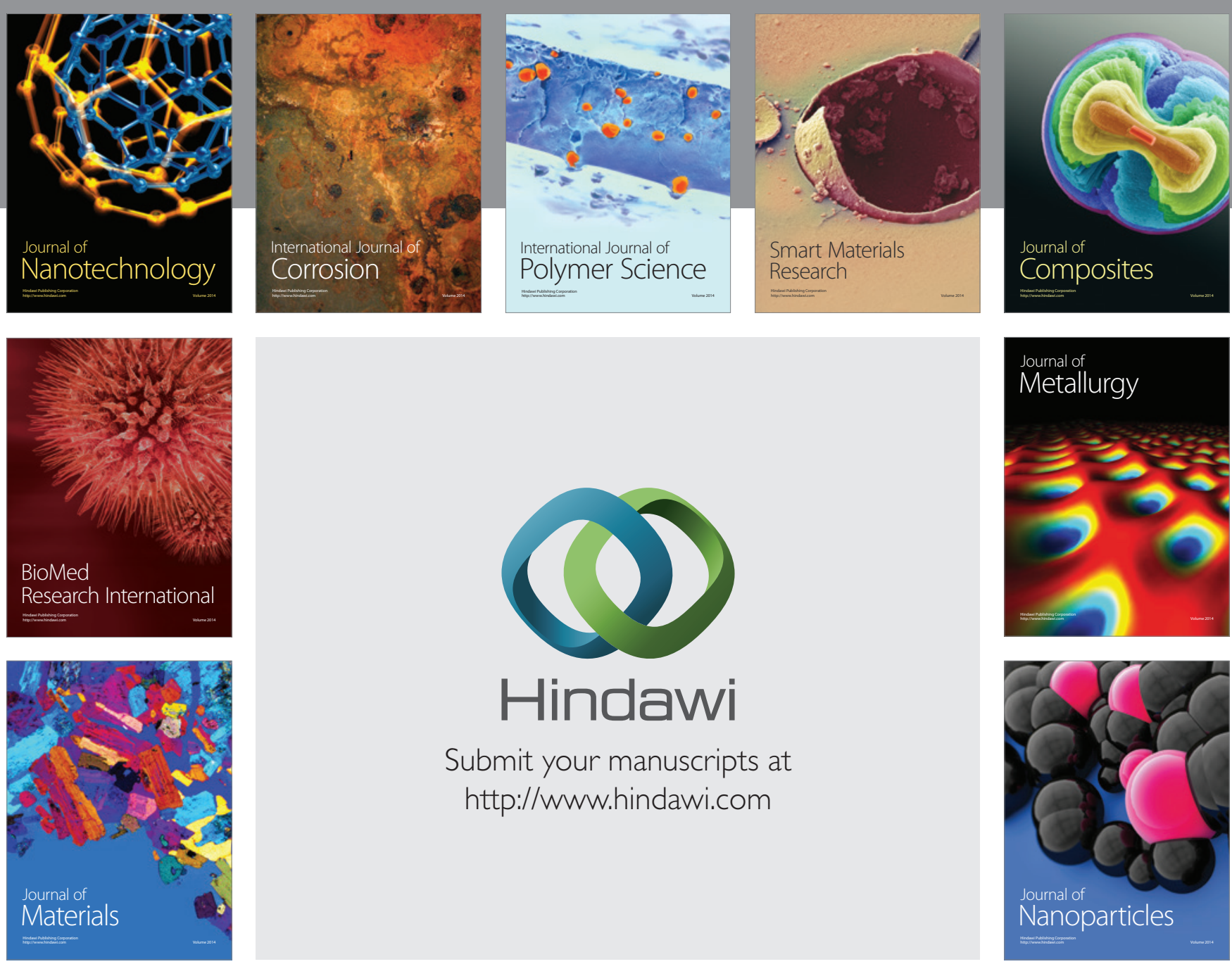

Submit your manuscripts at http://www.hindawi.com
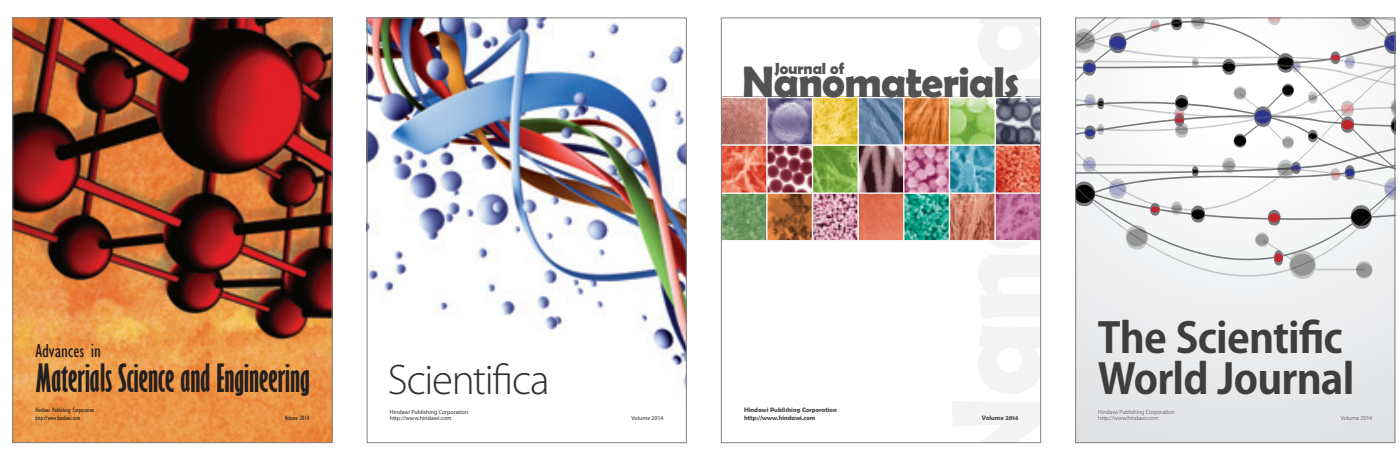

\section{The Scientific World Journal}
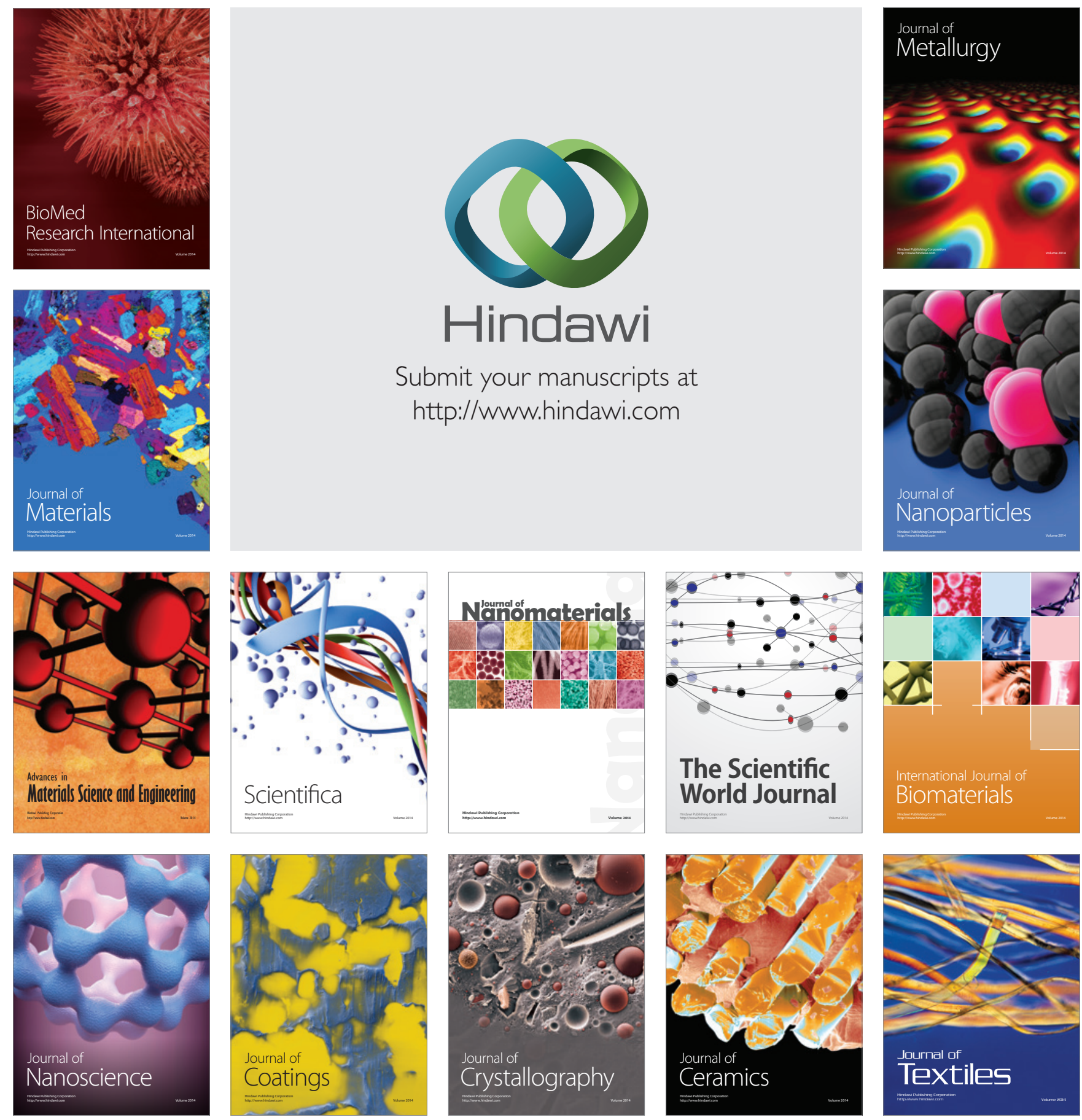